\title{
Conceptual Design of Information Systems based on Enterprise Modelling
}

\author{
H. Grabowski, G. Grein, P. Milde, U. Weber \\ Computer Science Research Center (FZI) \\ Haid-und-Neu-Str. 10-14, 76131 Karlsruhe, Germany. \\ Telephone: +49 721-9654-532. Fax: +49 721-9654-509. \\ email:gr@rpk.mach.uni-karlsruhe.de,grein@fzi.de, \\ milde@fzi.de,weber@fzi.de.
}

\begin{abstract}
Many companies are faced with the problem of having to optimize their business processes. There is an imminent need for a consistent Business Reengineering, particularly of those planning sectors preceding manufacturing, such as sales, design / development and planning, allowing a product development which is both efficient and oriented towards customer's demands. Currently, reengineered business processes have to be adapted to the functionality of standard software in order to achieve a good coordination between the processes within a company and suitable software that supports these processes. Enterprise Modelling is a promising instrument emphasizing on technical process requirements. It can be used as a performance specification for the conceptual design, selection and configuration of information systems.
\end{abstract}

\section{Keywords}

Enterprise Modelling Tool, Business Reengineering, Process Modelling, Information System

\section{INTRODUCTION}

The success of companies depends not only on products and services geared to market requirements, but more and more on the processes and methods used to produce them. It is for this reason, that optimizing company-specific activity sequences and business processes has to be seen as the main task to be undertaken. 
The comprehensive satisfaction of the needs of not only external but also internal customers has to be considered. Today, this integrated, workflow-oriented way of reorganizing and optimizing processes within a company is called Business Reengineering.

Previous activities in the field of rationalization and efficiency measures are restricted mainly to manufacturing sectors, and therefore possible efficiency potentials in these areas for reducing production cost and shortening door-to-door-time are nearly exhausted.

Departments prior to the actual manufacturing, such as sales, engineering design or production planning, have in many respects been disregarded up to now. However, the main product characteristics such as quality features, production cost and time-to-market are decisively determined within these sectors. Additionally, the processes in these departments take up $60-80 \%$ of the door-to-door time and $75 \%$ of the workforce (Peters, 1988).

These are the reasons why business processes - often subdivided by department barriers have to be optimized with the help of Business Reengineering. In order to cope with the complexity which is characterized by

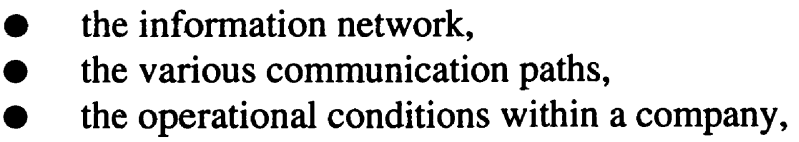

the planning sectors preceding manufacturing must be analyzed and documented starting from the outset. However, this documentation is often recorded in a condition that prevents subsequent and integrated reutilization e.g. for reengineering the company, conceptual design of information systems or specification of workflow management systems (Fraser, 1994).

Besides the problem of an efficient documentation usage, the discrepancy between technical process requirements and functionality of available standard software is another basic problem. Currently, the business processes have to be adapted to the capability of standard software to achieve a good coordination between the processes within the company and suitable software, that has to support these processes (process-adaptation). This processadaptation can cause a serious setback concerning efficiency of process flow and economic viability particularly after reengineering and optimizing business processes. Softwareadaptation is usually impossible to realize because present information systems can rarely be adapted and support only isolated activities instead of connected processes.

In the case of software-adaptation, the company-specific terminology, the information structures, the proven and well-tried processes and therefore the individuality of the company can be kept. Disadvantages or difficulties arise from release changes, because the specific modifications and expansions of the software have to be adapted with considerable expenditure.

\section{APPROACH}

An approach to solve the conflict between software- and process-adaptation is shown in the following. This approach uses a computer-assisted Enterprise Model for the conceptual design and adaptation of software. 
Such an Enterprise Model is able to replace traditional performance specifications by specifying requirements for the selection or implementation of information systems (Figure 1). There are usually different specialized information systems used to support the order processing. Therefore an integrated Enterprise Model is necessary to coordinate the separate individual systems in use. For example, having an Enterprise Model enables the integration of engineering data management systems (EDMS) and computer-aided production planning and control systems. It particularly helps with the coordination of the requirement specifications by sharing tasks that have to be performed by various systems in use.

Furthermore, such an Enterprise Model guarantees the definition of basic data by the specification of data schemes which are needed for an integrated use of information systems. Depending on the field of application either individual software has to be implemented or standard software has to be adapted specifically to the requirements of each company. This decision is influenced by economic viability as well as strategic reasons.

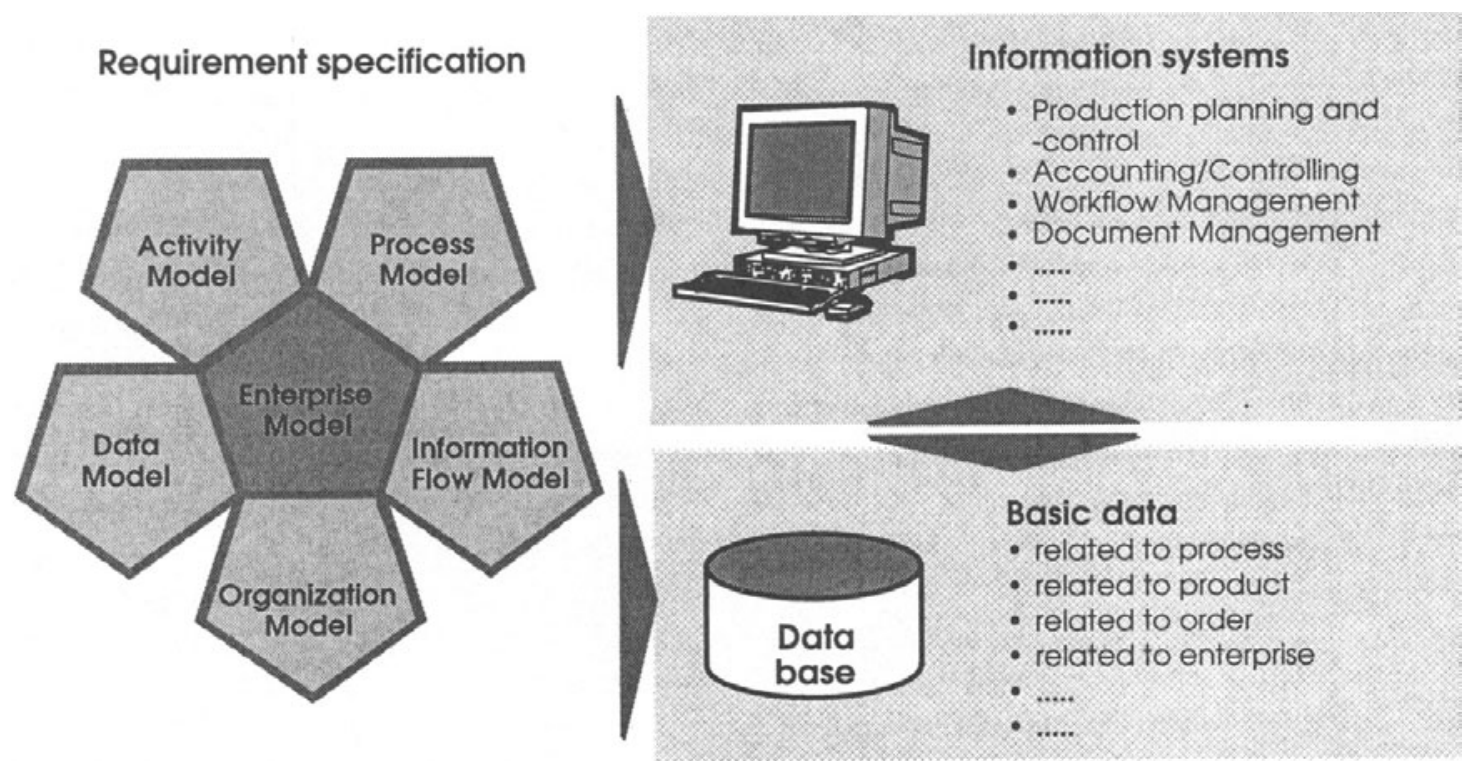

Figure 1 Approach for the conceptual design of information systems based on an Enterprise Model

The basis for this approach is an object-oriented designed Enterprise Model, which is defined as follows:

An Enterprise Model is an abstract representation of enterprise objects and their dependencies based on functional, stuctural and behavioural similarities. It describes consistently all relevant views (world of discourse) on an enterprise (real world).

These views are characterized by an abstraction reducing the real world's complexity. An integrated Enterprise Model then consists of a redundance-free conjunction of partial models. 
In order to design information systems the following has to be specified:

- all activities that have to be necessarily performed within the context of order processing;

- the connecting information flows;

- the describing data;

- the sequence of the process steps;

- the organizational responsibilities for carrying out these process steps.

These views can be classified as belonging to partial models. Each one of them refers to different aspects of the real enterprise as shown above (Figure 1, left side).

Depending on the extent of refinement, the activity model - which is designed following a certain hierarchy - contains the description of areas of responsibility down to single work steps (activities). Furthermore, input and output information has to be depicted, which is either necessary for the execution of the activities or a result of the execution.

The information flow model has a structure similar to networks and distinguishes between information on the one hand and information carriers on the other. It links the objects of the activity model by defining the source and destination of each information. The data model further specifies the information and information carriers in order to obtain a database structure. In completion to the activity model, process steps and their organizational relations are represented as business processes within the process model. Decision rules can additionally be represented. The organization model which reflects the organizational structure of the company is closely connected with the process model. The relations of organizational units to certain process steps point out the competences and authorities and determine responsibilities for carrying out these steps.

Formal graphical description methods enable the representation of all required views on an enterprise in an easy, clearly arranged and unequivocal way. For the individual partial models the following graphical description methods are chosen:

- SADT (Structured Analysis and Design Technique) (Ross, 1985) to represent the activity and information flow model;

- extented flow diagrams representing the process model;

- OOA (Object-Oriented Analysis) following Coad and Yourdon (1991) for data modelling;

- organization charts for representing the organizational model.

The modelled structures define who, in which business process, at which moment carries out which activity, which information a person needs and to whom work results have to be forwarded. The knowledge of these relationships is a fundamental prerequisite for the design of information systems. This is denoted in (Griethuysen, 1992) as the view of the Enterprise Model on information systems. 


\section{CONCEPTUAL DESIGN OF INFORMATION SYSTEMS}

The knowledge of the relationships which are typical for a certain company shows that not the functional sectors are to be organized to the highest degree. Instead, the company in its entirety and the benefit for the customer are of paramount importance. Due to this, a Business Reengineering that realizes an integrated and process-oriented information processing concept is becoming more and more evident (Mertins, Jochem and Jäkel, 1994, Wiegershaus, Schönheit, Becker and Fink, 1994).

Hammer and Champy (1993) have originally coined the term 'Business Reengineering' and propagate a complete new design of all existing business processes within a company. In opposition to this, a new approach is introduced: It is based on optimizing existing processes. It puts the main emphasis on the working methods and the possible computer assistance.

The basic approach is oriented towards the following six levels:

1. Fixing of enterprise strategies and targets.

2. Carrying out an actual-performance analysis and establishing an Enterprise Model.

3. Planning Business Reengineering within the Enterprise Model (i. e. establishing a target conception).

4. Designing and implementing information systems.

5. Realization of Business Reengineering within the enterprise.

6. Setting up information systems.

In the following, the conceptual design of an information system (level 4) is described in detail (Figure 2). This design is based on the drawn-up target conception (level 3), which is represented by the Enterprise Model. Simultaneously, the target conception should be realized in order to have it nearly completed before setting up the information system.

Designing information systems demands the consideration of three aspects:

- static aspects represented by the data structure;

- dynamic aspects (procedures) of the information system concept comprise both software features and operation mode;

- organizational aspects determining authorization and views within the information system.

In order to use an Enterprise Model as a performance specification for the conceptual design of information systems, it is necessary to transform - within the Reengineering recorded and at least in the model already optimized - company processes into the three aspects mentioned above. Using an example, Figure 3 shows the transformation steps which are described in the following. 


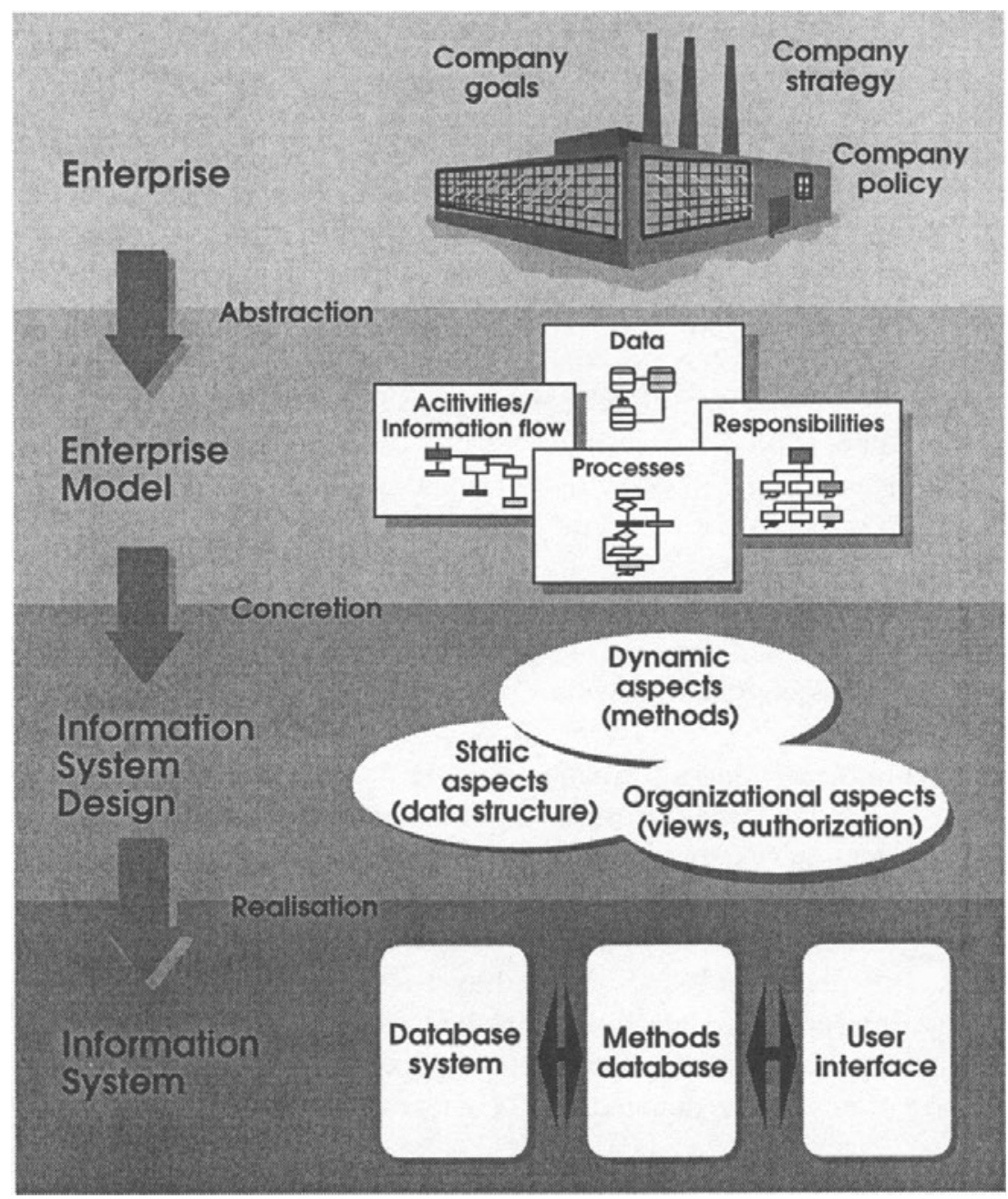

Figure 2 Methodological design of information systems in the context of Enterprise Modelling

The first concretion step concerns the transformation of the data model into the data structure (static aspects) of the information system that has to be designed. Within the Enterprise Model object-oriented depicted objects, their attributes and relationships can be transformed into Entity-Relationship-Models or EXPRESS specifications. As a result, it is possible to derive database schemes from these formal descriptions nearly automatically (Grabowski, Anderl and Polly, 1993).

As already stated above, dynamic aspects (procedures) of the information system concept comprise both software features and operation mode. The tasks described in the activity model substantially predefine the necessary functions of the system. Within the design process it is for example necessary to execute the activity 'Check standards' after creating a drawing. At this point, the relevant drawings are checked as to relevant standards and guiding rules. The subsequent release or modification demand depends on the test results. The relationships, that are described in the activity model, allow the direct definition of the system feature 'Check Standards'. 


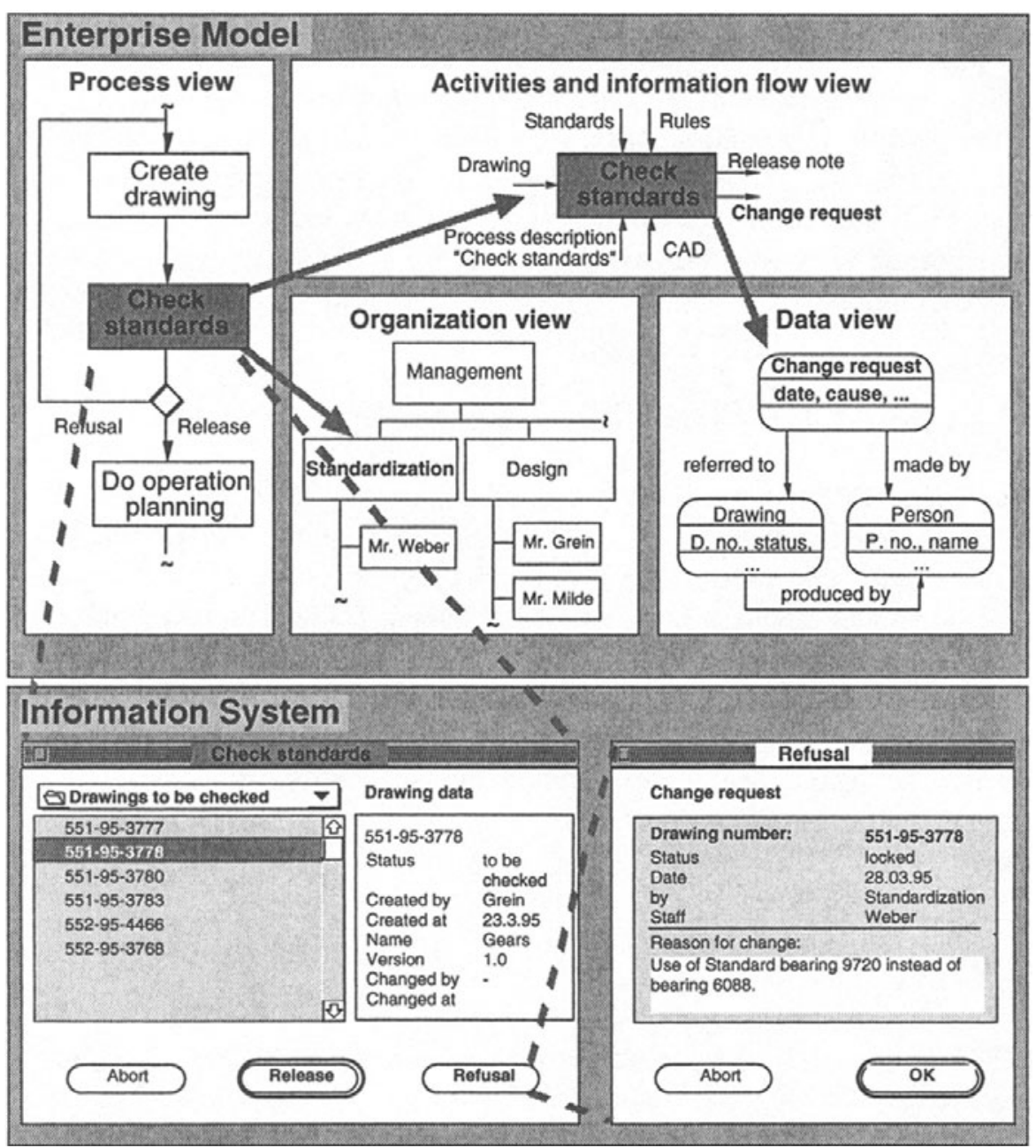

Figure 3 Example of transformations of the process step 'Check standards' from the Enterprise Model into the information system

The process model with the workflow-oriented data additionally determines the operation mode, which is the sequence of the needed system functions. In the example this sequence depends on the test results. In case of a release, the process step 'Do operation planning' succeeds, otherwise there is a loop back to the process step 'Create drawing'. A consequent realization of the process model requirements enables an utmost support of the business processes by information technology.

The combination of the organization model and the process model enables the determination of authorization to parts of the information system (organizational aspects). By the assignment of organizational units to single process steps, for example as persons responsible, consultants or persons to be informed, access mechanisms can be defined. After a check of standards and the release of the CAD-model a design engineer receives read-only access to the data he could edit unrestrictedly before.

Finally, based on all partial models the contents of the user interface masks can be defined. They represent the required information for specific tasks and the execution of system 
functions. The execution of the process step 'Check standards' demands a mask that shows the user the drawings to be checked together with all organizational data. Additionally, it must be possible to assign a release note as well as a modification demand.

With the help of this information system concept a new implementation or adaptation of already existing software can be realized. Especially, in case of standard software (such as production planning and -control or workflow management systems with an open architecture) a new implementation is usually not economical, so this concept rather represents the basis for the individual adaptation.

\section{PRISMA - A TOOL FOR ENTERPRISE MODELLING}

Based on many years of experience in the area of Enterprise Modelling, a software tool called PRISMA is being developed at the Computer Science Research Center (FZI) in Karlsruhe, Germany. This system originates from a methodology for planning of computer integrated information systems and business processes (Grabowski, Schäfer and Krzepinski, 1992). The PRISMA-Tool is implemented in Smalltalk-80, an object-oriented programming language. Smalltalk-80 was chosen, because it is based on a so-called virtual machine, which guarantees hardware independence. Therefore, PRISMA can be used on MacOS, Windows and various Unix platforms. The current state of development enables the user to:

- represent organizational structures;

- record business processes;

- describe all activities and information flows within a company;

- built up OOA and ER data models.

Figure 4 schematically shows the current view-based concept of PRISMA.

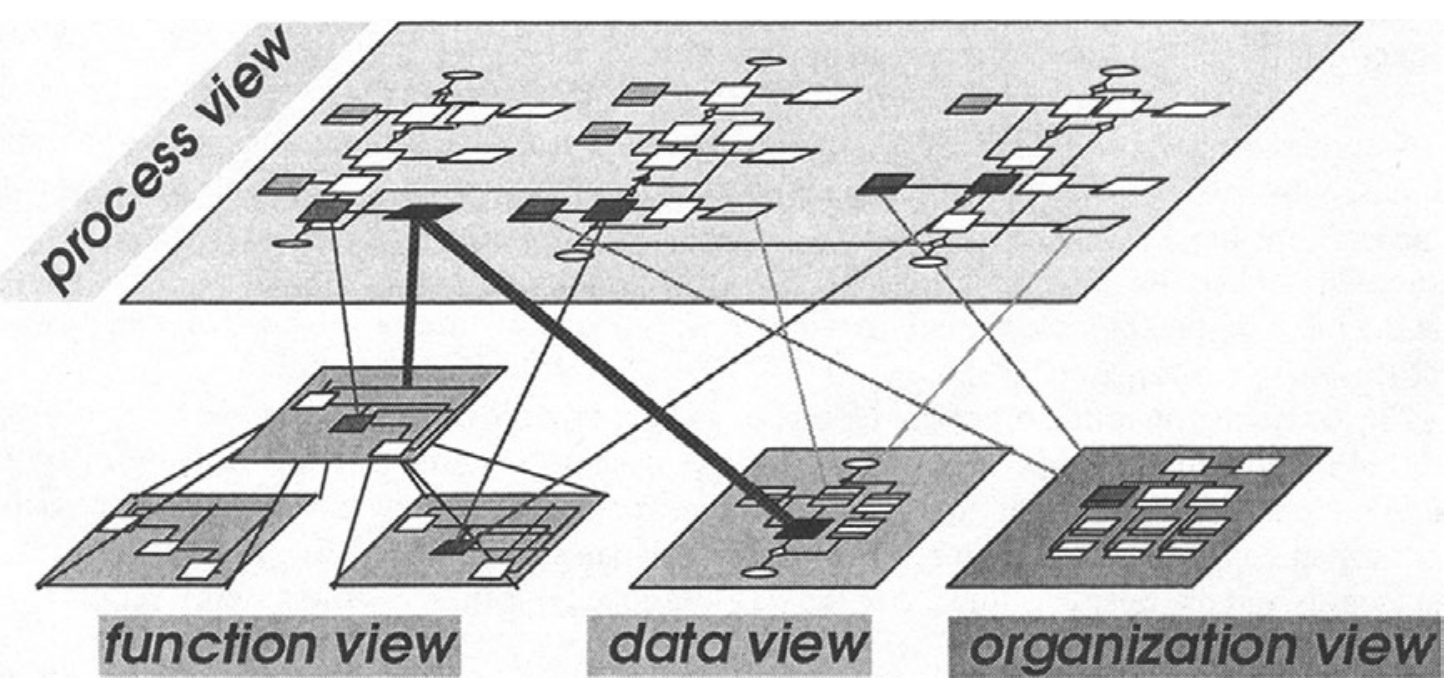

Figure 4 PRISMA's view-based concept 
The linking of the different views on the Enterprise Model is realized by reference mechanisms. Objects, which occur in more than one view, are connected via the process module. This approach reduces the trouble for maintaining redundant view contents and keeping their consistency. A change of objects in one view causes an update of all other relevant views. The bold links in figure 4 emphasize this connection.

The following three figures show an extract of an enterprise model of one of our industrial partners. They give an idea of PRISMA's functionality and its user interface.

Our projects usually begin with analyzing and modelling organizational structures of the company. Figure 5 depicts a strictly hierarchical organization. The window in front gives additional information - about a selected organizational unit - that is not graphically represented in this editor. In our example the design department is chosen. The data entries result from references to the same enterprise object (design department) in other views and its connection to other objects e.g. processes or process steps. The entries in the information field 'References' show all processes in which the design department is involved and 'responsible for' indicates those process steps the selected person 'Dr. Seiler' is responsible for.

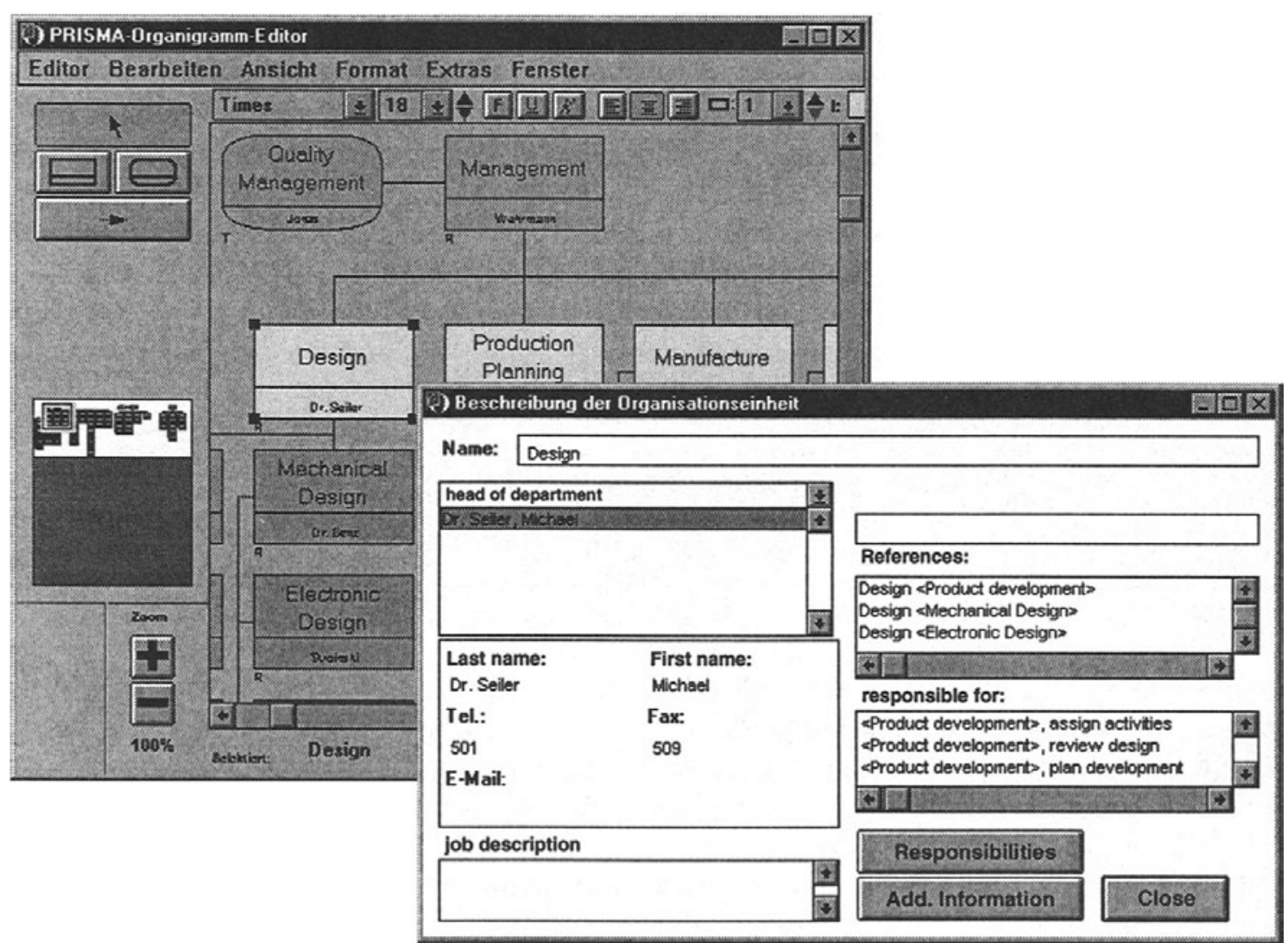

Figure 5 User interface of PRISMA's organization modelling module

Supporting a process- and activity-oriented proceeding PRISMA offers two more modules. The process modeller provides a symbol set for graphic-oriented modelling of the process organization. Figure 6 shows an extract of a Product Development process. The process steps 
arranged in the center are connected by black bold workflow arrows. Organizational units such as 'Mechanical Design' are placed on the left side. Grey arrows indicate their responsibilities for certain process steps. Parallelograms placed on the right side (such as 'design documentation') represent important in- and outputs of single process steps.

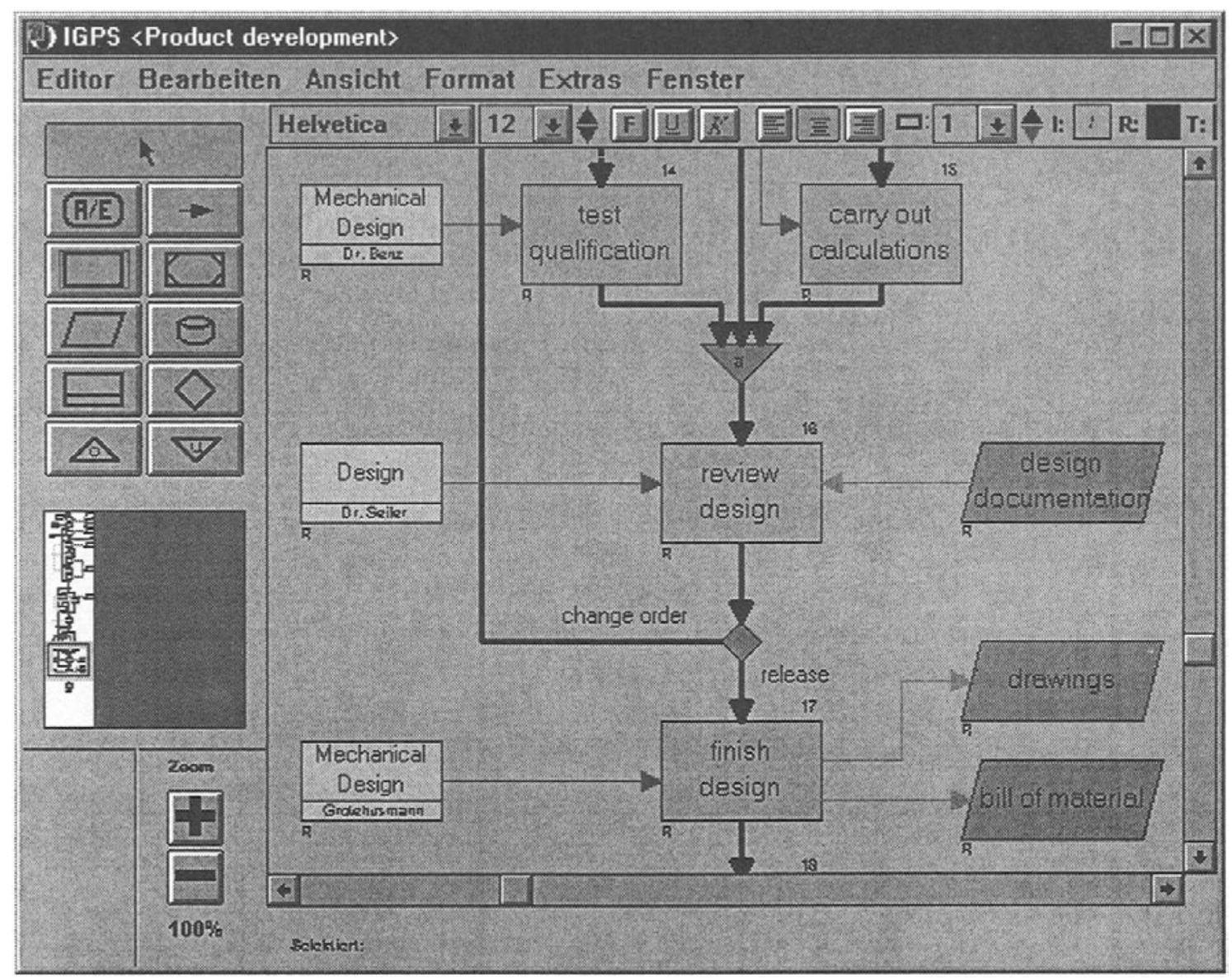

Figure 6 PRISMA's process modelling module

In order to optimize processes and define information demands of single process steps it is necessary to take a closer look at activities and their connecting information flows. Therefore, PRISMA provides a function modeller following the SADT notation. Figure 7 shows activities which refer to the process steps of Figure 6. The workflow information is now missing, of course. But working in this view allows to describe all needed and created information of each activity. The window in the back shows additional information e.g. about a selected information flow. Therefore, with PRISMA it is possible to browse both source and destinations of every information flow.

PRISMA has already been used for several consulting projects. Besides reorganization and optimization of business processes, the efficient introduction of future-oriented quality management systems according to ISO 9000 is an important field of application (Grabowski, Grein and Milde, 1995). 
The graphic-oriented modelling technique and the easy handling lead to a high acceptance among our industrial partners. After only a few training lessons even non-expert users are capable of maintaining the enterprise model on their own, so that PRISMA becomes an essential part of the established quality management system.

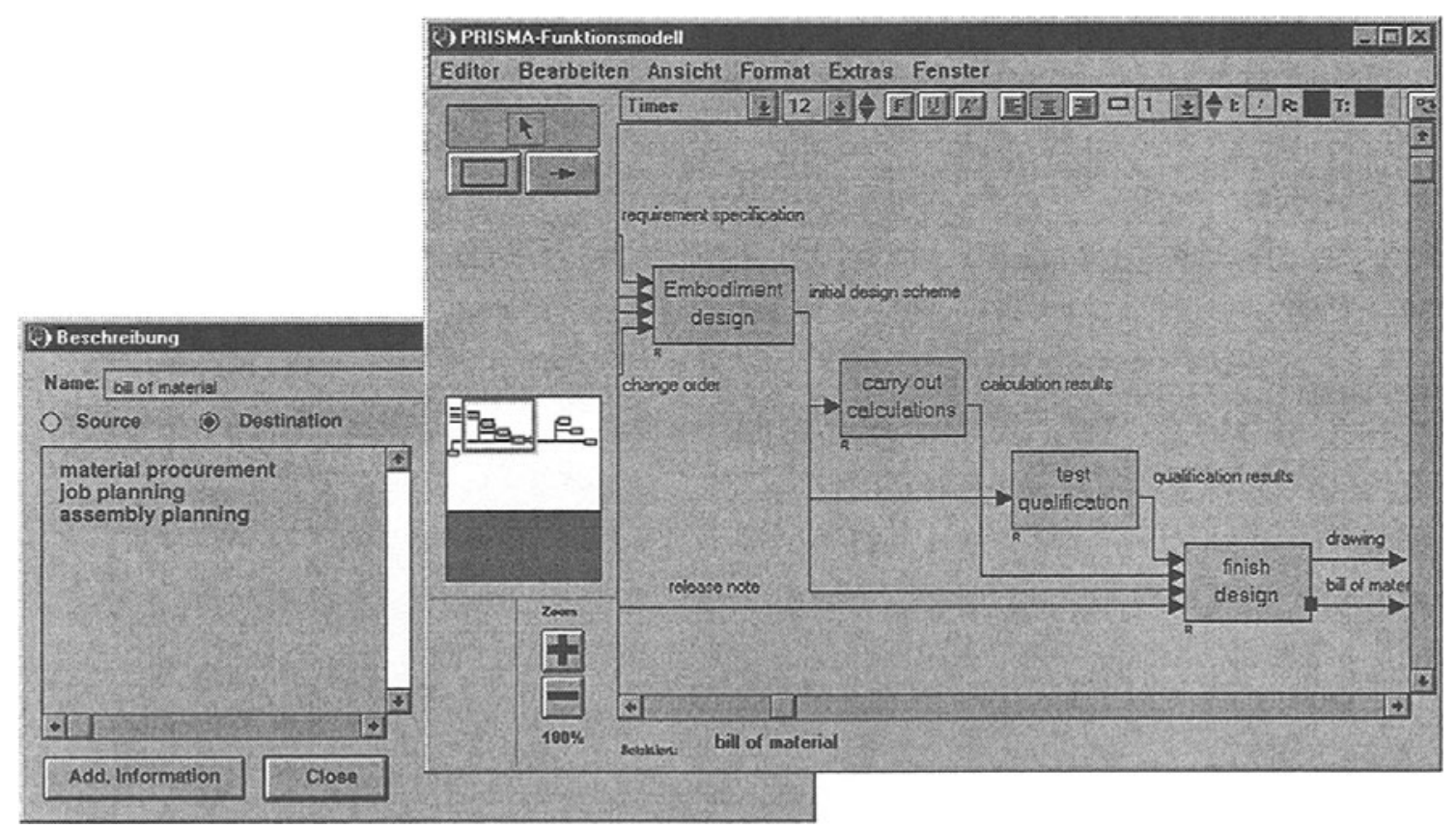

Figure 7 PRISMA's function modelling module

The current modules of PRISMA provide fundamental functions, which have to be further developed with regard to the conceptual design of information systems that meet technical process requirements. One major task into this direction is the full integration of all editors in order to describe a company consistently. A full integration is a prerequisite for the automatic execution of the transformation steps.

\section{CONCLUSIONS AND FUTURE WORK}

For planning, controlling and supervising goal-oriented processes in the context of Business Reengineering all relevant aspects within the order processing have to be methodically analysed first and then formally described by a computer-assisted object-oriented Enterprise Model. The data that such an Enterprise Model contains can simultaneously be used for a target conception of business processes and the conceptual design of supporting information systems.

This proceeding enables the adaptation of company services to the increasing requirements of customers by optimizing business processes. The conceptual design of information systems is then realized by means of the transformation principles outlined herein. The proceeding focuses mainly on the technical requirements from the reorganized enterprise processes. The 
supporting software systems will then match with these requirements as far as possible (software-adaptation).

Recent information systems mainly support singular integrated business processes rather than entire enterprise operations. Therefore, it is efficient to execute the transformation steps after isolating the relevant parts of the Enterprise Model that are effected by the process in focus.

For further development of existing Enterprise Modelling software computer-aided methods and tools have to be provided for supporting an automatic execution of these transformation steps, which means building a bridge from Enterprise Modelling to Information System Design.

\section{REFERENCES}

Coad, P. and Yourdon, E. (1991) Object-Oriented Design, Englewood Cliffs, New Jersey.

Fraser, J. (1994) Managing Change through Enterprise Models, in: Milne, R. and Montgomery, A. eds. (1994) Applications and Innovations in Expert Systems II, SGES Publications, Cambridge.

Grabowski, H., Schäfer, H. and Krzepinski, A. (1992) PRISMA-Instrumentarium zur methodisch unterstützten Planung und Integration betriebsspezifischer CAD/CAMVerfahrensketten, CIM Management 82.

Grabowski, H., Anderl, R. and Polly, A. (1993) Integriertes Produktmodell, Beuth Verlag, Berlin.

Grabowski, H., Grein, G. and Milde, P. (1995) Zukunftsorientiertes Qualitätsmanagement nach DIN ISO 9000 ff., CIM Management 11 3, p. 57-61.

Griethuysen, J.J. van (1992) Enterprise Modelling, A Necessary Basis for Modern Information Systems, in: Meer, J. de; Heymer, V.; Roth, R. (eds): Proceedings of the IFIP TC6/WG6.4 International Workshop on Open Distributed Processing Berlin 1991, North Holland.

Hammer, M. and Champy, J. (1993) Reengineering the Corporation, Harper Collins Publisher, New York.

Mertins, K., Jochem, R. and Jäkel, F.-W. (1994) Reengineering und Optimierung von Geschäftsprozessen, ZwF 89 10, p. 479-481.

Peters, G (1988) Ablauforganisation und Informationstechnologie im Büro, Konzeptionelle Überlegungen und empirisch-explorative Studie, Müller Botermann Verlag, Köln.

Ross, D. T. (1985) Applications and Extensions of SADT, IEEE Transactions on Software Engineering 114 , p. 25-33.

Wiegershaus, U., Schönheit, M.; Becker, A. and Fink, M. (1994) Reengineering der Geschäftsprozesse - Worthülse oder zukunftsweisende Methode?, VDI-Z 136 11/12, p. 31-34. 


\section{BIOGRAPHY}

o. Prof. Dr.-Ing. Dr. h. c. Hans Grabowski, born 1934, since 1975 director of the Institute for Computer Science and Application in Planning and Design (RPK) at the University of Karlsruhe, since 1985 director of the CAD/CAM research department of the Computer Science Research Center (FZI), Karlsruhe, Germany.

Dipl.-Wirtsch.-Ing. Gunther Grein, born 1967, studied Economical and Mechanical Engineering at the University of Karlsruhe, since 1992 scientific assistant at the CAD/CAM research department of the Computer Science Research Center (FZI), Karlsruhe.

Dipl.-Ing. Peter Milde, born 1966, studied Mechanical Engineering at the University of Karlsruhe, since 1992 scientific assistant at the CAD/CAM research department of the Computer Science Research Center (FZI), Karlsruhe.

Dipl.-Ing. Ulrich Weber, born 1963, studied Mechanical Engineering at the University of Karlsruhe, since 1991 scientific assistant at the CAD/CAM research department of the Computer Science Research Center (FZI), Karlsruhe. 